\title{
Tumour suppressor EP300, a modulator of paclitaxel resistance and stemness, is downregulated in metaplastic breast cancer
}

\author{
Muhammad Asaduzzaman ${ }^{1,5} \cdot$ Stephanie Constantinou ${ }^{1,6} \cdot$ Haoxiang Min ${ }^{1}$. \\ John Gallon ${ }^{1}$ - Meng-Lay Lin ${ }^{1} \cdot{\text { Poonam } \text { Singh }^{2} \cdot \text { Selina } \text { Raguz }^{3} \cdot \text { Simak Ali }}^{1}$. \\ Sami Shousha ${ }^{2}$ R. Charles Coombes ${ }^{1}$ Eric W.-F. Lam ${ }^{1} \cdot$ Yunhui Hu$^{4}$. \\ Ernesto Yagüe ${ }^{1}$
}

Received: 6 February 2017 / Accepted: 13 March 2017/Published online: 24 March 2017

(c) The Author(s) 2017. This article is an open access publication

\begin{abstract}
Purpose We have previously described a novel pathway controlling drug resistance, epithelial-to-mesenchymal transition (EMT) and stemness in breast cancer cells. Upstream in the pathway, three miRs (miR-106b, miR-93 and miR-25) target EP300, a transcriptional activator of E-cadherin. Upregulation of these miRs leads to the downregulation of EP300 and E-cadherin with initiation of an EMT. However, miRs regulate the expression of many genes, and the contribution to EMT by miR targets other than EP300 cannot be ruled out.

Methods We used lentiviruses expressing EP300-targeting shRNA to downregulate its expression in MCF-7 cells as well as an EP300-knocked-out colon carcinoma cell line. An EP300-expression plasmid was used to upregulate its expression in basal-like CAL51 and MDA-MB-231 breast cancer cells. Drug resistance was determined by short-term
\end{abstract}

Electronic supplementary material The online version of this article (doi:10.1007/s10549-017-4202-z) contains supplementary material, which is available to authorized users.

Yunhui $\mathrm{Hu}$

417501784@qq.com

$\triangle$ Ernesto Yagüe

ernesto.yague@imperial.ac.uk

1 Division of Cancer, Imperial College Faculty of Medicine,

Hammersmith Hospital Campus, Du Cane Road,

London W12 0NN, UK

2 Centre for Pathology, Department of Medicine, Imperial College Faculty of Medicine, Charing Cross Hospital, Fulham Palace Rd, London W6 8RF, UK

3 Division of Clinical Sciences, Imperial College Faculty of Medicine, Hammersmith Hospital Campus, Du Cane Road, London W12 0NN, UK proliferation and long-term colony formation assays. Stemness was determined by tumour sphere formation in both soft agar and liquid cultures as well as by the expression of CD44/CD24/ALDH markers. Gene expression microarray analysis was performed in MCF-7 cells lacking EP300. EP300 expression was analysed by immunohistochemistry in 17 samples of metaplastic breast cancer.

Results Cells lacking EP300 became more resistant to paclitaxel whereas EP300 overexpression increased their sensitivity to the drug. Expression of cancer stem cell markers, as well as tumour sphere formation, was also increased in EP300-depleted cells, and was diminished in EP300-overexpressing cells. The EP300-regulated gene signature highlighted genes associated with adhesion (CEACAM5), cytoskeletal remodelling (CAPN9), stemness (ABCG2), apoptosis (BCL2) and metastasis (TGFB2). Some genes in this signature were also validated in a previously generated EP300-depleted model of breast cancer using minimally transformed mammary epithelial

4 The 3rd Department of Breast Cancer, China Tianjin Breast Cancer Prevention, Treatment and Research Center, National Clinical Research Center of Cancer, Tianjin Medical University Cancer Institute and Hospital, Huan Hu Xi Road, Ti Yuan Bei, He xi District, Tianjin 300060, People's Republic of China

5 Present Address: Department of Clinical Pharmacy and Pharmacology, University of Dhaka, Dhaka 1000, Bangladesh

6 Present Address: MRC Cancer Unit, Hutchison/MRC Research Centre, Cambridge CB2 0XZ, UK 
cells. Importantly, two key genes in apoptosis and stemness, $B C L 2$ and $A B C G 2$, were also upregulated in EP300knockout colon carcinoma cells and their paclitaxel-resistant derivatives. Immunohistochemical analysis demonstrated that EP300 expression was low in metaplastic breast cancer, a rare, but aggressive form of the disease with poor prognosis that is characterized by morphological and physiological features of EMT.

Conclusions EP300 plays a major role in the reprogramming events, leading to a more malignant phenotype with the acquisition of drug resistance and cell plasticity, a characteristic of metaplastic breast cancer.

Keywords Metastasis - Cancer stem cells - Drug resistance $\cdot \mathrm{BCL} 2 \cdot \mathrm{ABCG} 2 \cdot \mathrm{EP} 300$ signature

$\begin{array}{ll}\text { Abbreviations } \\ \text { ALDH } & \text { Aldehyde dehydrogenase } \\ \text { CSC } & \text { Cancer stem cell } \\ \text { DMEM } & \text { Dulbecco's modified Eagle medium } \\ \text { EMT } & \text { Epithelial-to-mesenchymal transition } \\ \text { IC }_{50} & \text { Drug concentration producing 50\% cell death } \\ \text { miR } & \text { Micro RNA } \\ \text { MTMEC } & \begin{array}{l}\text { Minimally transformed mammary epithelial } \\ \text { cell }\end{array} \\ \text { QPCR } & \text { Quantitative PCR }\end{array}$

\section{Introduction}

Many breast cancers initially respond well to chemotherapy, however, in a significant proportion of cases, and following a cancer-free period, metastases at distant sites appear and these are accompanied by a poor response to therapy, normally with fatal consequences. It is thus imperative to improve our understanding of the mechanisms leading to cancer spread and therapy response with the aim of developing new markers and therapeutic strategies [1].

Epithelial cells undergoing epithelial-to-mesenchymal transition (EMT, the first step in the metastatic cascade) lose E-cadherin expression and their characteristic epithelial morphology. These events are accompanied by an increase in motility and acquisition of the ability to degrade the extracellular matrix and invade other tissues. Loss of E-cadherin, a hallmark of the EMT programme, liberates $\beta$-catenin (normally associated with the C-terminus of E-cadherin), which migrates to the nucleus and induces the expression of genes orchestrating the EMT programme. Importantly, the EMT programme generates cancer cells with stem cell-like characteristics (cancer stem cells, CSCs). EMT and CSCs are often associated with the acquisition of drug resistance. Thus, these three processes are tightly interlinked [2-4].
Downregulation of E-cadherin by transcriptional repressors (Snail and Slug, as well as ZEB1, ZEB2 and Twist) is well-studied. However, transcriptional activators of E-cadherin, which help maintain the cell in an epithelial state, such as EP300, FOXA1 and RUNX1, are less well characterized [5]. EP300 was originally discovered as a transcriptional co-activator that plays pivotal roles in integrating and mediating multiple signal-dependant transcription events [6]. The most studied function of EP300 is as a histone acetyltransferase, regulating transcription via chromatin remodelling [7], and it has important roles in cell proliferation, transformation and differentiation [8]. Loss of EP300 heterozygosity has been described in breast carcinomas [9], somatic EP300 mutations have been identified in several malignancies [10] and EP300-deficient colon carcinoma cells show phenotypic changes characteristic of EMT [11].

We have recently described a novel EMT/CSC/drug resistance regulatory axis controlled by the miR-106b $\sim 25$ cluster [12], which is associated with aggressive basal-like, oestrogen receptor-negative, grade 3 breast cancers [13]. The three miRs in the cluster target EP300 mRNA and downregulate its expression, leading to increased motility and invasive properties as well as the generation of doxorubicin and radiation-resistant derivatives [12]. In bladder cancer cells, experimental downregulation of EP300 also leads to doxorubicin and cisplatin resistance [14], [15]. Using a minimally transformed mammary epithelial cell model [16], we have also demonstrated that cells in which this pathway has been experimentally downregulated acquire a multidrug resistance phenotype with evasion from apoptosis [17].

Here we show that experimental modulation of EP300 alters paclitaxel sensitivity and the generation of paclitaxel resistance. EP300 silencing is also associated with increased in vitro tumorigenicity and CSC-like markers, whilst its ectopic expression in basal-like breast cancer cells partly rescues the epithelial, differentiated and paclitaxel-sensitive phenotype. Gene expression profiling identifies down-stream EP300 targets associated with drug resistance, EMT and CSCs. Finally, immunohistochemical analysis reveals a strong downregulation of EP300 in metaplastic breast cancer, a rare, but aggressive form of invasive breast cancer with histological evidence of EMT, which has a poor clinical outcome.

\section{Materials and methods}

\section{Cells}

MCF-7 and MDA-MB-231 cells were obtained from Sigma-Aldrich, CAL51 cells from the German Resource 
Centre for Biological Material (DSMZ), HCT116 and HCT-KOEP300 (a genetic EP300 knockout from HCT116 cells [11]) cells from Cancer Research Technology and HEK293T cells from the American Type Culture Collection. Minimally transformed human mammary epithelial cells (MTMEC) were a gift from William Hahn (Dana Farber, Boston). MTMECs express TERT, SV40 large T antigen, a constitutively active form of PI3K, p110 $\alpha$ and oncogenic ras [16] and were maintained in serum-free HuMEC medium (Life Technologies). HEK293T were maintained in DMEM supplemented with $4.5 \mathrm{~g} / \mathrm{L}$ glucose, $10 \%$ foetal calf serum and $4 \mathrm{mM}$ L-glutamine (Life Technologies). MCF-7 and MDA-MB-231 cells were maintained as HEK293T cells but with $1 \mathrm{~g} / \mathrm{L}$ glucose. HCT116 cells were maintained in McCoy's 5A medium supplemented with $10 \%$ foetal calf serum and $4 \mathrm{mM}$ L-glutamine.

Downregulation of EP300 was obtained by stable expression of hairpins in the lentiviral vector $\mathrm{pGIPZ}^{\circledR}$ (Thermo Scientific). Two different hairpins,

V3LHS_331296 (mature antisense: TGTGCACAAC TGTTTGCCG) and V3LHS_331295 (mature antisense: TAATCTATCTTCAGTAGCT), from the RNAi Consortium (Broad Institute) were used. Viral transductions were essentially as described [18] and cells were selected and maintained with $1 \mu \mathrm{g} / \mathrm{mL}$ puromycin. Overexpression of EP300 was obtained by stable expression of a pcDNA3.1derived construct carrying the full-length EP300 cDNA (Addgene \#23252) [19]. Cells were transfected with GenJet (SignaGen Laboratories) following manufacturer's instructions and selected and maintained with $1 \mathrm{mg} / \mathrm{mL}$ G418. Pools of at least 200 G418-resistant clones were used in all cases. Paclitaxel-resistant lines were generated following a "pulse" methodology as described [12]. In short, cells were treated with paclitaxel (20 nM for MCF7-shEP300, $15 \mathrm{nM}$ for MTMEC-shEP300 and $40 \mathrm{nM}$ for HCT-KOEP300 derivatives) for 3 days, after which the cells were grown drug-free for two passages before repeating the drug treatment. Resistant lines were obtained after several months and did not show any significant cell death after drug treatment.

\section{Gene expression analysis}

Total RNA (isolated using a RNeasy kit, Qiagen) was reverse transcribed with MuLV reverse transcriptase (High-Capacity RNA-to-cDNA kit, Applied Biosystems) and real-time quantitative PCR (QPCR) was performed using SYBR Green (Applied Biosystems) on an ABI Prism 7700 detection system (PerkinElmer Life Sciences). RPS14 and RPLPO mRNAs were used as normalizers. A comparative threshold cycle was used to determine the relative gene expression as previously described [20]. Oligonucleotides used for gene expression analysis are shown in Supplementary Table 1 .

\section{Antibodies}

Antibodies for immunodetection following standard immunoblotting procedures were 24E10 for E-cadherin (Cell Signalling Technology), ab10485 for EP300 (Abcam), AC-15 (ab6276; Abcam) for $\beta$-actin and Bcl-2 (100) [sc-509] and C-5 (sc-365962) for Lamin B1 (Santa Cruz Biotechnology). Membranes were incubated with antirabbit (926-32213, IRDye ${ }^{\circledR} 800 \mathrm{CW}$ Donkey anti-Rabbit, LI-COR) and anti-mouse (926-68072, IRDye ${ }^{\circledR}$ 680RD Donkey anti-Mouse, LI-COR) secondary antibodies and the bands were visualised and quantified using an Odyssey Infrared Imaging System (LI-COR Biotechnology-UK Ltd).

\section{Drug sensitivity assay}

The drug concentration necessary to kill $50 \%$ of cells $\left(\mathrm{IC}_{50}\right)$ after 3 days of culture (6-well dishes; 3000 cells/ well) was obtained after sulphorhodamine B (SigmaAldrich) staining [21] as previously described [22].

\section{Drug resistance clonogenic assay}

Cells $\left(2 \times 10^{5}\right)$ were seeded, at least in triplicate, in 25 $\mathrm{cm}^{2}$ culture flasks and exposed to a single dose of paclitaxel (Tocris Bioscience) for 3 days. Cells were kept in culture for 21 days with drug-free medium changes every three days. Drug-resistant clones were fixed with $4 \%$ paraformaldehyde and stained with $0.2 \%$ crystal violet and counted.

\section{Anchorage-independent growth assays}

To assess the capacity of CSCs to propagate in an anchorage-independent manner, both soft agar and sphere assays were performed. Cells $\left(5 \times 10^{4}\right)$ were seeded in $0.3 \%$ agar noble in complete DMEM medium on $30 \mathrm{~mm}$ plates with a bottom layer of solidified $0.6 \%$ agar noble in the same medium. Triplicate cultures for each cell type were maintained for 4 weeks at $37{ }^{\circ} \mathrm{C}$ in an atmosphere of $5 \% \mathrm{CO}_{2}$ and $95 \%$ air, with $200 \mu \mathrm{L}$ fresh medium added once a week. Colonies larger than $50 \mu \mathrm{m}$ in diameter were counted after 4 weeks and stained with crystal violet. For the sphere formation assay [23], cells (100-200) were plated in each well of an ultralow attachment 24-well plate (Corning) with $3 \mathrm{~mL}$ serum-free mammary epithelial growth medium (MEGM, BioWhittaker), supplemented with $2 \%$ B27 supplement, $20 \mathrm{ng} / \mathrm{mL}$ epidermal growth factor and $20 \mathrm{ng} / \mathrm{mL}$ fibroblast growth factor-basic (all from Invitrogen). Cells were grown for 14 days, replenishing $500 \mu \mathrm{L}$ of medium every 3-5 days, until spherical clusters larger than $50 \mu \mathrm{m}$ diameter were counted. 


\section{Flow cytometry}

For stem cell markers, CD44 (G44-26, APC) and CD24 (ML5, PE), both from BD Biosciences, were used essentially as described [23]. An Aldefluor assay kit (StemCell Technologies) was used for the determination of aldehyde dehydrogenase (ALDH) activity by flow cytometry essentially as described [23]. Briefly, cells were resuspended in assay buffer $\left(10^{6}\right.$ cells $\left./ \mathrm{mL}\right)$. Activated Aldefluor substrate $(5 \mu \mathrm{L})$ was added to samples and incubated at $37{ }^{\circ} \mathrm{C}$ for 45 min to allow substrate conversion. A sample with the ALDH inhibitor diethylaminobenzaldehyde was used as a negative control.

\section{Microarray hybridization, processing and data analysis}

Total RNA was prepared from three independent biological replicates of each cell line using a RNeasy Kit (Qiagen). RNA integrity was evaluated using an Agilent 2100 Bioanalyzer. cDNA synthesis and further processing was performed using GeneChip WT PLUS Reagent kit (Affymetrix). Hybridization to Affymetrix GeneChip Human Gene ST Arrays followed manufacturer's protocol. The control probes used to measure microarray hybridization efficiency were obtained from the Affymetrix online database and were filtered out before analysis. Raw signal intensity, background correction, quantile normalization, $\log _{2}$ transformation and probeset summarization were performed with Affymetrix Expression Console Software. Differential gene expression was analysed using Partek Genomic Suite (Partek, USA). The microarray data were deposited with the NCBI Gene Expression Omnibus (http:// ncbi.nlm.nih.gov/geo/) under accession number GSE76200.

\section{Immunohistochemistry}

A total of 17 FFPE metaplastic breast cancer samples and 17 normal (reduction mammoplasty/benign) breast tissue samples were used. Samples were collected from the Imperial College Healthcare Tissue Bank (R14086) and Breast Cancer Now Tissue Bank (BCNTB-TR000054) after ethics approval by both institutions. Immunohistochemical staining was performed using antibodies against EP300 (HPA003128, Sigma-Aldrich, dilution 1:200) and E-cadherin (Clone 36, \#610181, BD Biosciences, dilution 1:200). EP300 antibody specificity was validated with a synthetic peptide (APrEST73567, Atlas Antibodies) competition assay following manufacturer's protocol. A standard operating procedure for immunohistochemical staining (Charing Cross Hospital Histopathology Laboratory, Q-Pulse index Code: CEL-LP-172-X, Ver. 1.6, 2013, Supplementary Table 2) modified to use the Bond Polymer
Refine Detection Kit (DS9800, Leica Biosystems) was used. All sections were visualised with diaminobenzidine and counterstained with haematoxylin. EP300 and E-cadherin immunoreactivity was scored based on staining intensity ranging from 0 to +3 : $0=$ null, $+1=$ low, $+2=$ intermediate and $+3=$ high, as described [24]. More than six representative fields of each slide were analysed for determining EP300 and E-cadherin expression levels. The percentage of EP300- or E-cadherin-positive tumour cells scored as high $(+2$ or +3 in at least $66 \%$ of cells) or low/none was calculated for each slide by two investigators (MA and EY) and validated by a pathologist (SS) and clinical oncologist (RCC).

\section{Statistical analysis}

Statistical evaluations were performed by Student's $t$ test for paired data or one-way ANOVA with Dunnett's multiple comparison test. Data were considered significant at a $P$-value inferior to 0.05 .

\section{Results}

\section{Modulation of EP300 in cell model systems}

In order to study how breast cancer epithelial cells respond to EP300 downregulation, we generated stably transfected MCF-7 cells with a lentivirus driving the expression of hairpins targeting EP300 mRNA. EP300 expression was high in this luminal cell line, but decreased to a high extent after the expression of two different EP300 hairpins. As expected, downregulation of EP300 led to a dramatic downregulation of E-cadherin (Fig. 1a).

HCT116 colon carcinoma cells are hemizygous for EP300 and due to the high frequency of homologous recombination in these cells, an EP300 genetic knockedout model showing characteristics of EMT, has previously been generated [11]. These cells show, as expected, a lack of both EP300 and E-cadherin (Fig. 1a) and thus represent also a good cell system to study the phenotypic effects in an EP300-null background.

Triple-negative, basal-like breast cancer cells show many mesenchymal characteristics and thus we generated stably transfected cells derived from CAL51 and MDAMB-231 in which EP300 was upregulated after transfection with an expression vector. Both CAL51 and MDA-MB-231 cells expressed low to moderate levels of EP300 that were upregulated in the stably overexpressed lines. As expected, E-cadherin was not detectable in the control cells, but its expression was upregulated in both CAL-EP300 and MDA-EP300 cells, although at a higher extent in the former than the latter (Fig. 1b). 

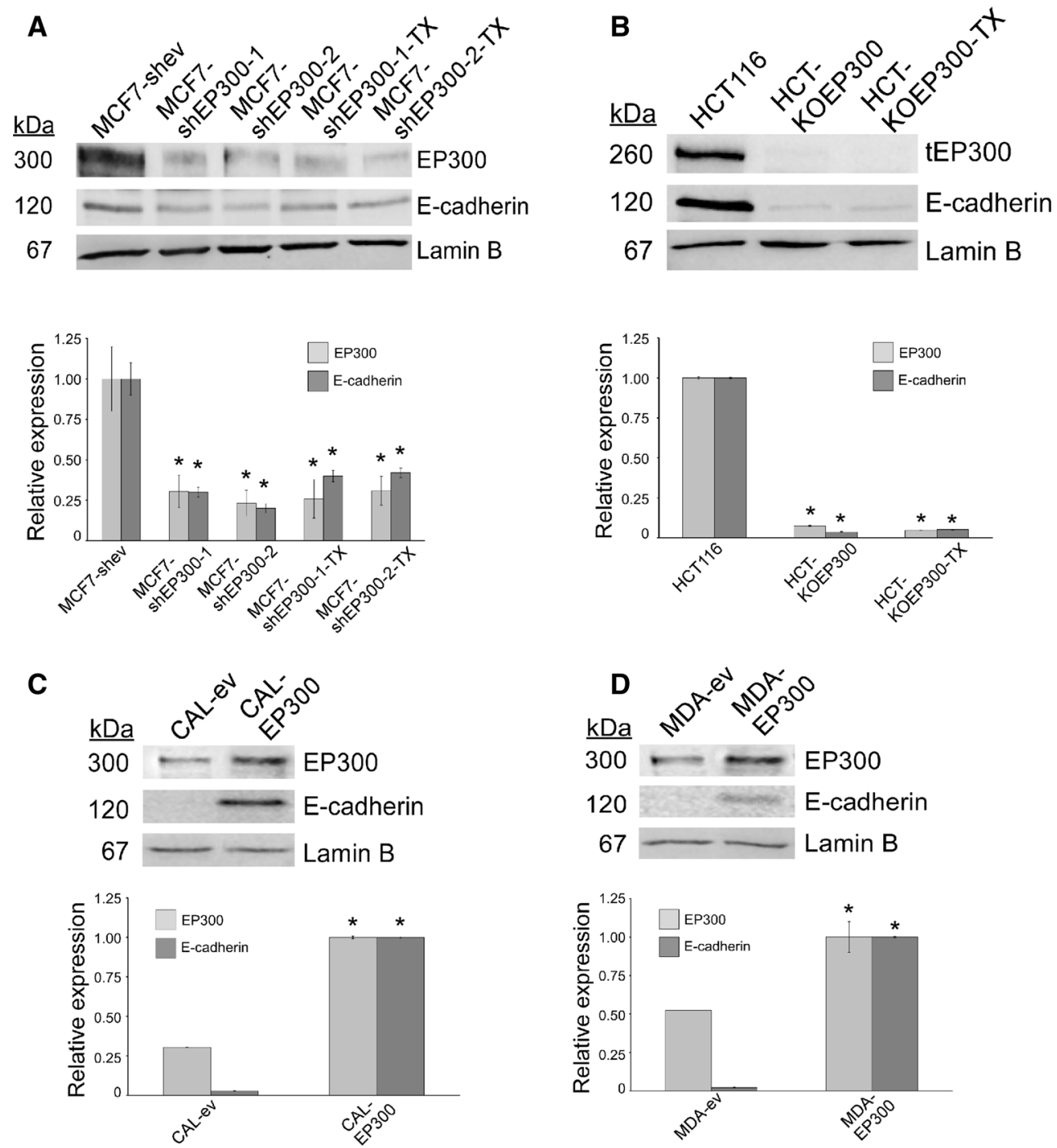

Fig. 1 Experimental modulation of EP300 in cellular models. Expression of EP300 and E-cadherin was determined by immunoblot analyses. a EP300 was downregulated in breast cancer luminal MCF7 cells by lentiviral expression of two different EP300 hairpins (MCF7-shEP300-1 and MCF7-shEP300-2). Cells expressing the empty pGIPZ vector (MCF7-shev) were used as control. b, a genetic knock-out of EP300 (HCT-KOEP300) is available in colon carcinoma HCT116 cells. This cell line is hemizygous for the EP300 locus and generates a C-terminus truncated EP300 protein [10]—note its lower molecular mass (tEP300, truncated EP300). Paclitaxel-resistant

\section{Modulation of EP300 expression alters paclitaxel sensitivity and the generation of paclitaxel-resistant cells}

Paclitaxel is used both in the primary setting to reduce the risk of recurrence and in the advanced stage after lack of response to anthracyclines. We have previously shown that in a minimally transformed cellular model of breast cancer, derivatives are indicated with the -TX name extension. c, d EP300 was upregulated in breast cancer basal-like CAL51 and MDA-MB231 cells with an EP300 expression cassette in pcDNA3.1 (CALEP300 and MDA-EP300). In both cases, cells transfected with pcDNA3.1 were used as controls (CAL-ev and MDA-ev). Lamin B was used as a loading control. Representative pictures of three replicates are shown. Immunoblots were quantified and data are shown in the histograms as average $\pm \mathrm{SD}$ of three blots. All statistical comparisons $(* P<0.05)$ versus control cells

experimental downregulation of EP300 decreases paclitaxel sensitivity and leads to the generation of paclitaxelresistant cells [17]. In order to ascertain the generalized effect on paclitaxel response, we determined its $\mathrm{IC}_{50}$ values in the cell models generated above. EP300 downregulation led to an increase in the $\mathrm{IC}_{50}$ in MCF-7 cells, giving between a 3.8- and 5.7-fold increase in resistance depending on the hairpin used (Table 1). Importantly, this 
Table 1 Modulation of paclitaxel sensitivity after experimental modulation of EP300 expression in cell models

\begin{tabular}{lllccc}
\hline Cell type & Cell derivative & EP300 status & $\mathrm{IC}_{50}(\mathrm{nM})^{\mathrm{a}}$ & Fold resistance & Fold sensitivity \\
\hline MCF7 & MCF7-shev & & 1.3 & & \\
& MCF7-shEP300-1 & Downregulated & 5.0 & 3.8 & \\
& MCF7-shEP300-2 & Downregulated & 7.5 & 5.7 & 35.1 \\
& MCF7-shEP300-1-TX & Downregulated & 45.6 & 22.7 & \\
\multirow{2}{*}{ HCT116 } & MCF7-shEP300-2-TX & Downregulated & 29.6 & & \\
& HCT116 & & 3.1 & & \\
& HCT-KOEP300 & Knockedout & 14.2 & 4.6 & \\
\multirow{5}{*}{ CAL51 } & HCT-KOEP300-TX & Knockedout & 53.0 & 17.1 & 3.5 \\
& CAL-ev & & 4.2 & & \\
MDA-MB-231 & MDA-ev & Upregulated & 1.8 & & \\
& MDA-EP300 & Upregulated & 9.2 & &
\end{tabular}

${ }^{a}$ Paclitaxel concentration at which proliferation after 3 days was reduced by $50 \%$ estimated from the corresponding dose-response curves increase in paclitaxel resistance was also reproduced in EP300-knocked-out colon carcinoma HCT116 cells with an $\mathrm{IC}_{50}$ increase of 4.6-fold (Table 1). Conversely, when EP300 was experimentally upregulated in CAL51 and MDA-MB-231 cells, an increase in paclitaxel sensitivity (2.3- and 3.5-fold, respectively) was observed (Table 1).

Modulation of EP300 did not only affect short-term drug sensitivity, but also the long-term generation of drug-resistant cells. After 3 weeks of culture, and following an initial single paclitaxel treatment during 3 days, the number of drug-resistant clones increased approximately fivefold in MCF7-shEP300 (Fig. 2a) and 15-fold in HCTKOEP300 cells (Fig. 2b). Conversely, overexpression of EP300 led to a reduction in the number of resistant clones by approximately three-fold in CAL-EP300 cells (Fig. 2c). When pools of resistant clones were isolated (MCF7shEP300-1-TX, MCF7-shEP300-2-TX and HCTKOEP300-TX), their paclitaxel $\mathrm{IC}_{50}$ values indicated a further decrease in drug sensitivity (Table 1). Thus, modulation of EP300 alters paclitaxel resistance.

\section{Modulation of EP300 expression alters cancer stem cell markers and anchorage independence}

Drug resistance is strongly associated with CSC characteristics, such as a CD $44^{+} / \mathrm{CD} 24^{-} / \mathrm{ALDH} 1^{+}$phenotype, and the ability to survive and grow in an anchorage-independent manner [25, 26]. We asked, first, whether modulation of EP300 would alter the proportion of CSCs. For this, we performed a double stain with CD44 and CD24 antibodies and determined the percentage of cells positive for each marker. As expected, MCF7-ev control cells showed a low proportion of $\mathrm{CD} 44^{+} / \mathrm{CD} 24^{-}$cells $(\sim 1 \%)$. However, there was an increase in both MCF7-shEP300 (to $2.5-3 \%)$ as well as in their paclitaxel-resistant derivatives

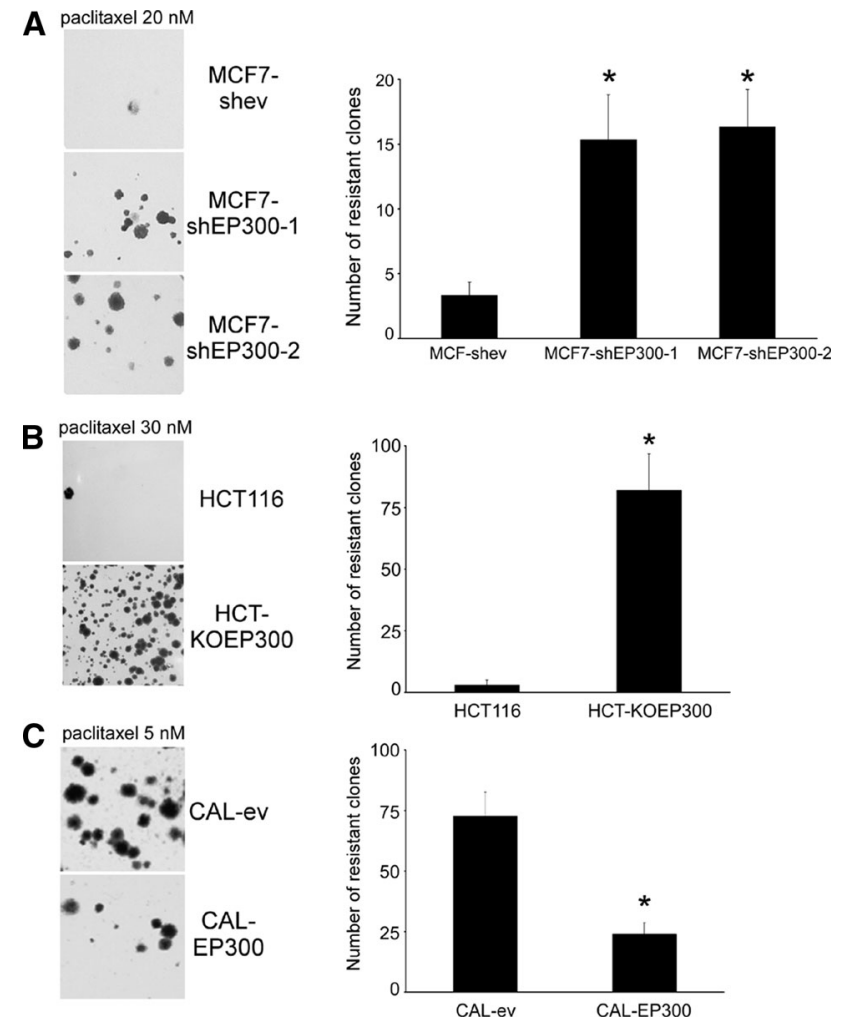

Fig. 2 EP300 regulates the generation of paclitaxel resistance. Cells were treated for 3 days with paclitaxel and drug-resistant clones were stained with crystal violet 3 weeks after (left panels) and counted (right panels). a, MCF-7 cells. b, HCT116 cells. c, CAL51 cells. Numerical data represent the average \pm SD of three independent experiments. All statistical comparisons $(* P<0.05)$ versus control cells. Pictorial data show a representative of three different experiments

(to 5-6\%; Fig. 3a). The increase in the $\mathrm{CD} 44^{+} / \mathrm{CD} 24^{-}$ population upon downregulation of EP300 was further confirmed using HCT116 cells. Although these cells have a high proportion of $\mathrm{CD} 44^{+} / \mathrm{CD} 24^{-}$cells, EP300 knock- 
down led to a further increase in this subpopulation, from $\sim 33 \%$ in HCT116 cells to $\sim 44 \%$ in HCT-KOEP300 cells, that increased further to $\sim 65 \%$ in HCT-KOEP300TX-resistant cells (Fig. 3b). Conversely, experimental upregulation of EP300 expression led to a decrease in the CD $44^{+} / \mathrm{CD} 24^{-}$subpopulation of MDA-MB-231 cells, from $\sim 9 \%$ in MDA-ev to $\sim 3 \%$ in MDA-EP300 cells (Fig. 3c). Despite its triple-negative and basal characteristics, CAL51 cells have a very low CD44 expression [27]. However, determination of $\mathrm{ALDH}^{+}$cells by flow cytometry confirmed that experimental upregulation of EP300 led to a decrease in the percentage of $\mathrm{ALDH}^{+}$CAL51 cells (from $\sim 43 \%$ in CAL-ev to $\sim 23 \%$ in CAL-EP300; Fig. 3d). Thus, there is an inverse relationship between EP300 expression and CSC markers.

In order to assess the functionality of the stem cell markers above, two complementary anchorage independence assays were performed, sphere formation in liquid cultures using low attachment plates and colony formation in soft agar. Downregulation of EP300 in MCF-7 cells led to an increase in both the number of mammospheres $(\sim 7$-fold $)$ and colonies in soft agar $(\sim 2$ fold). Paclitaxel-resistant derivatives showed a further two-fold increase in the number of mammospheres, although this was not observed in the formation of colonies in soft agar (Fig. 4a, d). These results were confirmed in HCT116 cells. Thus, the number of mammospheres increased two-fold and 3.5-fold in HCTKOEP300 and HCT-KOEP300-TX cells, respectively, whereas the number of colonies in soft agar increased by two-fold and 2.5-fold in the same cells (Fig. 4b, e). Conversely, CAL51 cells overexpressing EP300 showed a $50 \%$ reduction in the anchorage-independent growth efficiency (Fig. 4c, f). MDA-MB-231, which is a cell line notoriously recalcitrant for these types of assay [28], did not generate robust tumor spheres.

Overall, these results indicate a negative regulation of CSC characteristics by EP300.
A
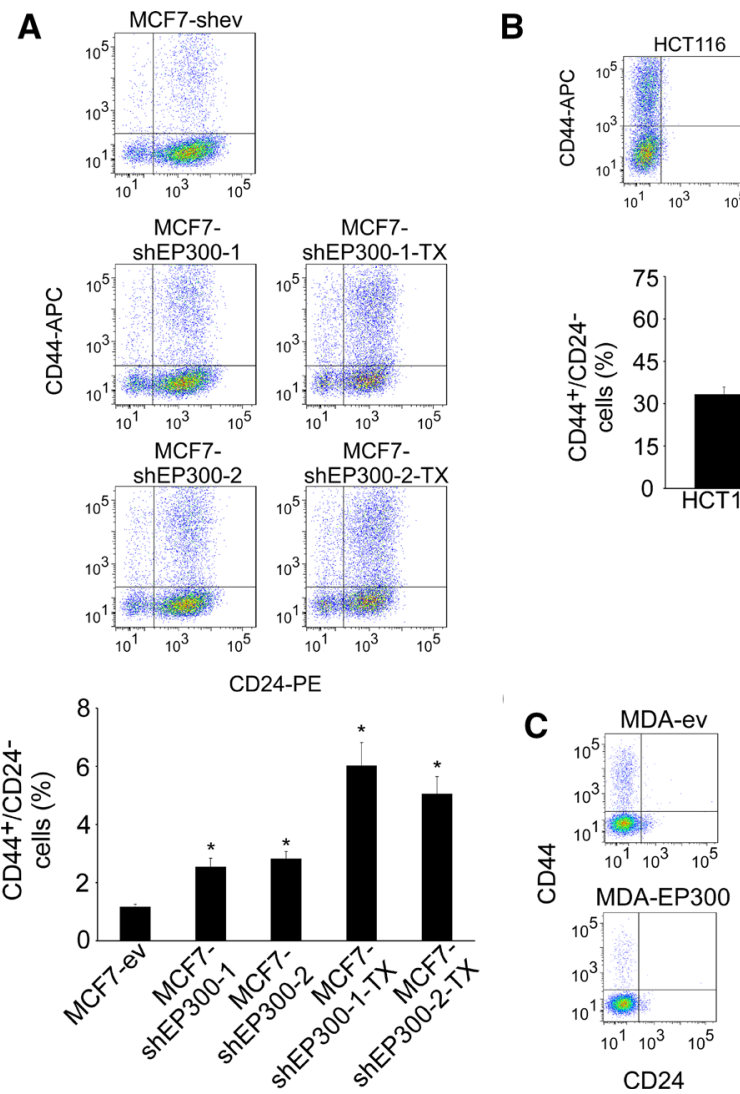

Fig. 3 EP300 regulates stem cell markers. a-c Flow cytometry plots after staining (a MCF-7 cells; b HCT116 cells; c MDA-MB-231 cells) with CD44-APC- and CD24-PE-conjugated antibodies. Paclitaxelresistant cell derivatives (MCF7-shEP300-1-TX, MCF7-shEP300-2TX and HCT-KOEP300) were generated from the corresponding cells after selection with $20 \mathrm{nM}$ (MCF-7 cells) and $40 \mathrm{nM}$ paclitaxel (HCT116 cells). Histograms indicate the percentage of $\mathrm{CD}_{4} 4^{+}$/ CD24- cells. d Upregulation of EP300 in CAL51 cells reduces the percentage of $\mathrm{ALDH}^{+}$cells. Cells were treated with Aldefluor alone
B

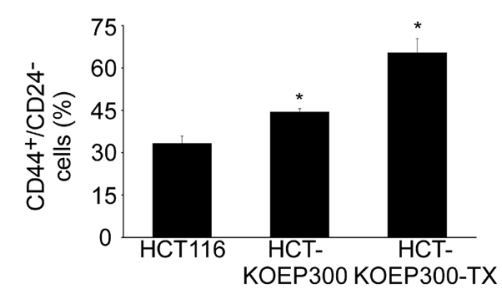

D
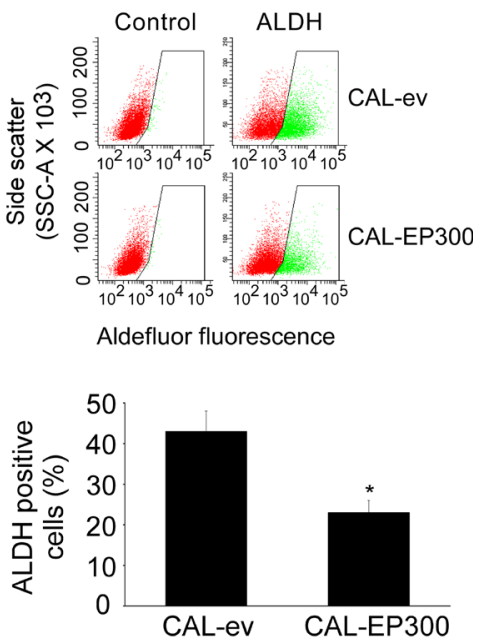

$(A L D H)$ or in the presence of the ALDH inhibitor diethylaminobenzaldehyde (Control) and then analysed by flow cytometry. The green gate was set up with the control cells to include no more than $1 \%$ of the population and was used to determine the percentage of ALDHpositive cells in the absence of inhibitor. Representative flow cytometry plots are shown. Numerical data represent the average \pm SD of three independent experiments. All statistical comparisons $(* P<0.05)$ versus control cells 

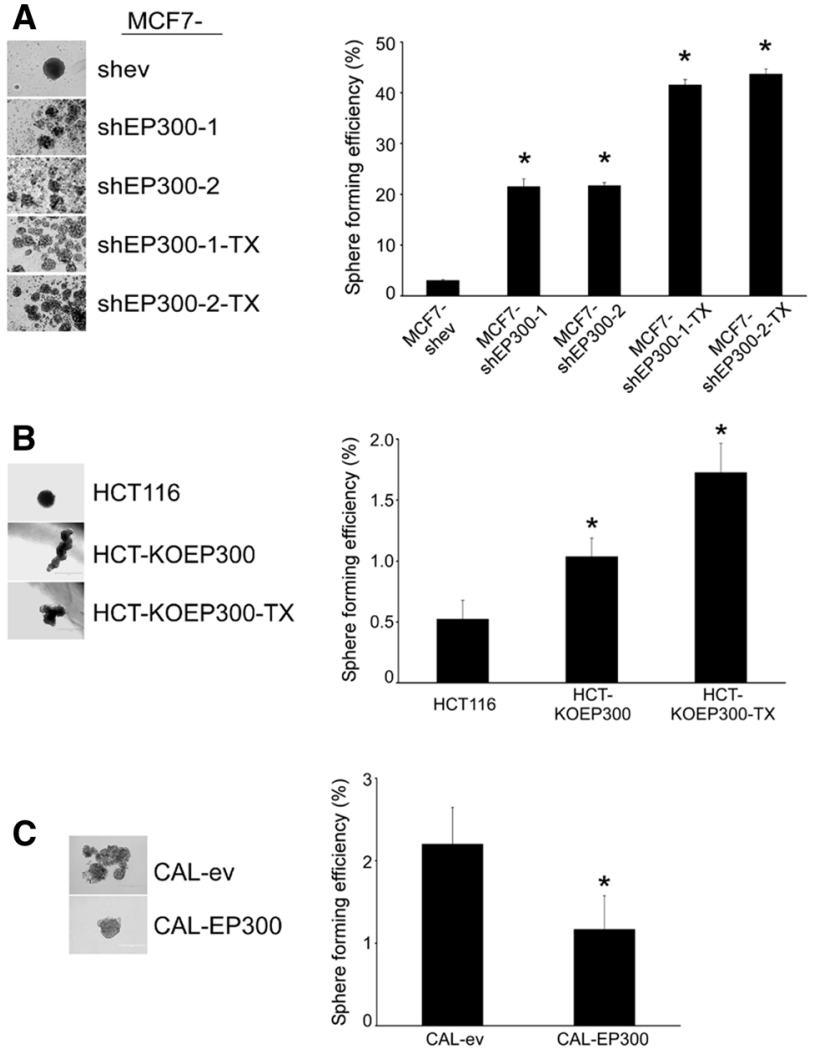

Fig. 4 EP300 regulates anchorage independence. Anchorage independence was determined by mammosphere formation in low attachment plates $(\mathbf{a}-\mathbf{c})$ and the formation of clones in soft agar $(\mathbf{d}-$ e) after 2 and 4 weeks, respectively. Representative pictures of at least three independent experiments are shown. Numerical data

\section{Genome-wide expression analysis indicates EP300 has a role in regulating adhesion, apoptosis and stemness}

In order to gain insights into the down-stream molecules regulated by EP300, and potential effectors of the phenotypes described above, a genome-wide expression profile analysis was performed in MCF7-shEP300 cells and their paclitaxel-resistant derivatives (Fig. 5a). As expected for a chromatin modifier and regulator of transcription, more than 4000 genes were differentially regulated upon EP300 downregulation and in paclitaxel-resistant derivatives (Fig. 5b). In order to validate the array data, in addition to EP300, the expression of another 10 genes was determined by QPCR. Expression of both up- and downregulated genes was highly reproducible between the two platforms (Fig. 5c), giving a high degree of confidence for the obtained gene expression profiles. The most differentially regulated genes are shown in Supplementary Table 3. Importantly, expression of key molecules in the MCF-7 signature, such as CEACAM5 (adhesion), CAPN9 (cytoskeletal remodelling), $A B C G 2$ (stemness), BCL2 and
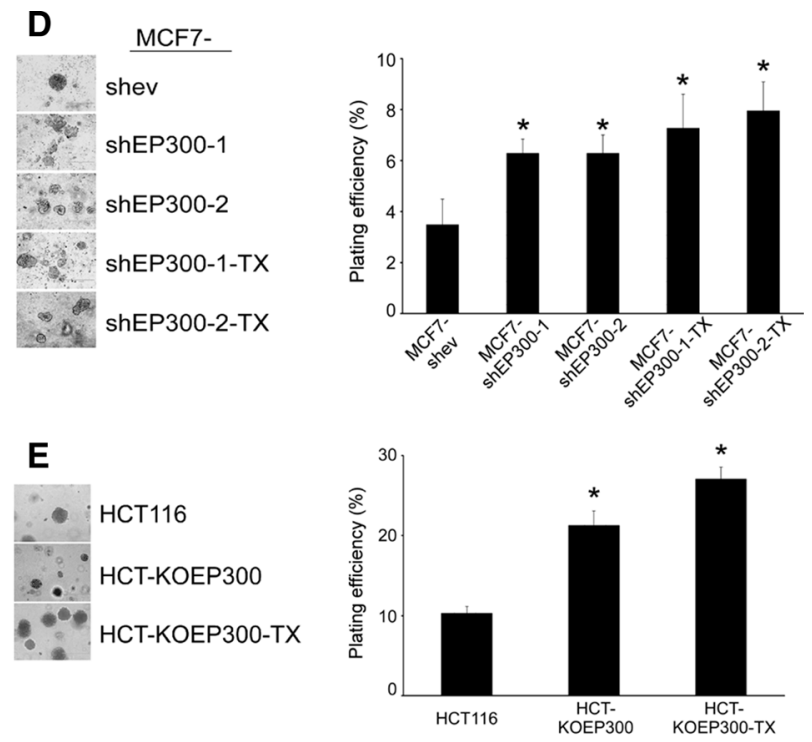

$\mathbf{F}$

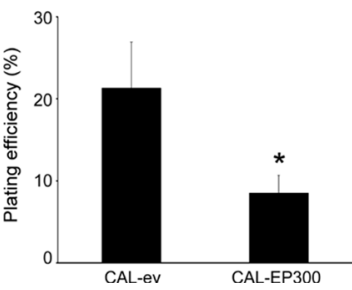

indicate the anchorage independence efficiency after counting tumour spheres larger than $50 \mu \mathrm{m}$ in diameter and is represented as the average $\pm \mathrm{SD}$ of three independent experiments. All statistical comparisons $(* P<0.05)$ versus control cells

TNFRSF11B (apoptosis), ITAG2 and ITAG3 (migration) and TGFB2 (metastasis), among others, was reproduced in MTMEC-shEP300 cells (Fig. 6a). Moreover, upregulation of BCL2 and ABCG2 was also demonstrated in both HCTKOEP300 cells and its paclitaxel-resistant derivative (Fig. 6b, c), indicating that regulation of these two important molecules involved in apoptosis response/drug resistance and stemness is not breast cancer specific and probably represents major EP300-regulated pathways.

\section{EP300 is downregulated in metaplastic breast} cancer

Metaplastic breast cancer is a rare (less than $1 \%$ of invasive breast cancers) and histologically diverse subtype of breast carcinoma with very poor prognosis. It shows the characteristics of cells undergoing EMT (spindle morphology, reprogramming of epithelial-mesenchymal markers), with acquisition of CSCs markers $\left(\mathrm{CD}_{4} 4^{+}\right)$and is more resistant to chemotherapy than basal-like or luminal cancers [29, 30]. As EP300 regulates most of the characteristics associated with these phenotypes, we asked whether EP300 
A

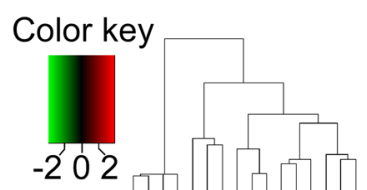

B

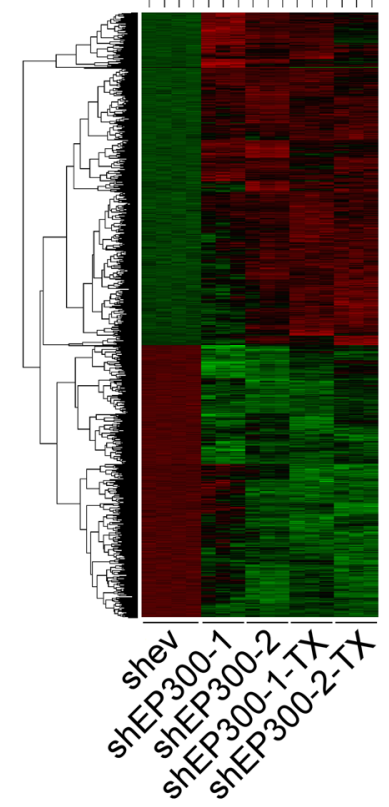

ShEP300-2 vs shev shEP300-1-TX vs shev

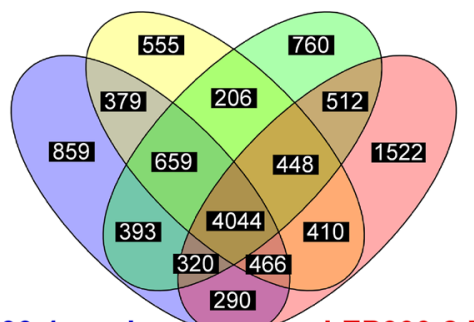

shEP300-1 vs shev shEP300-2-TX vs shev
C

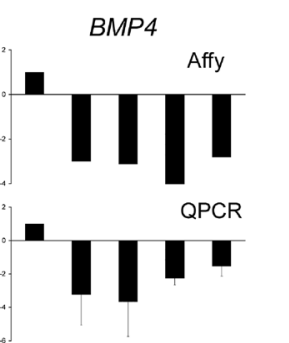

CEACAM5
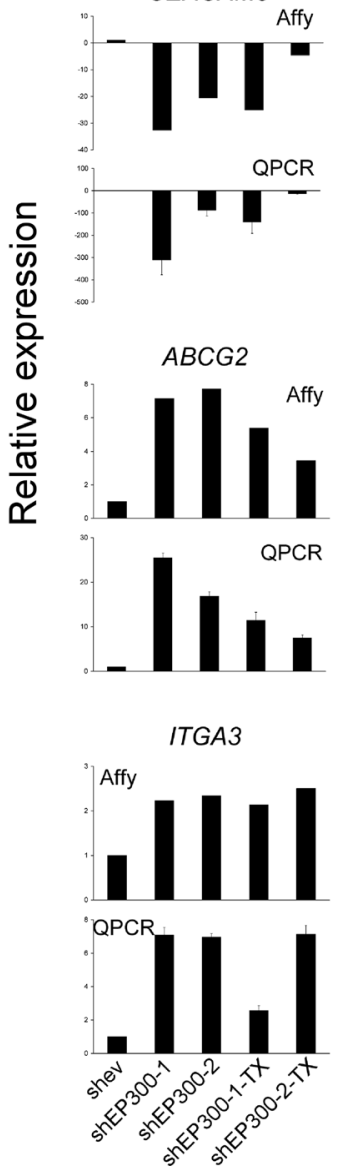
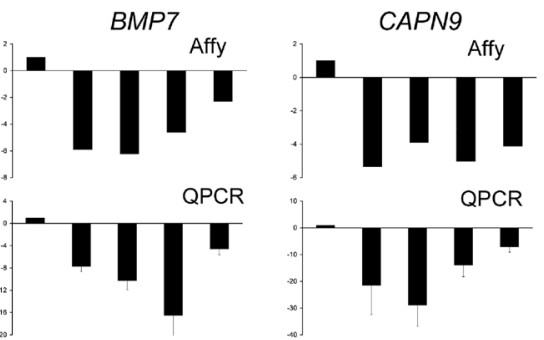

$E P 300$

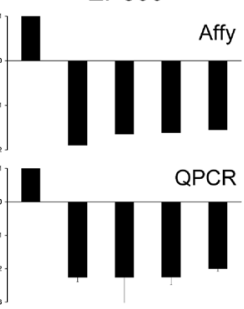

$B C L 2$

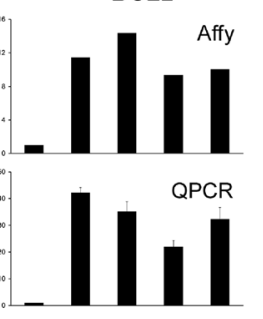

TGFB2

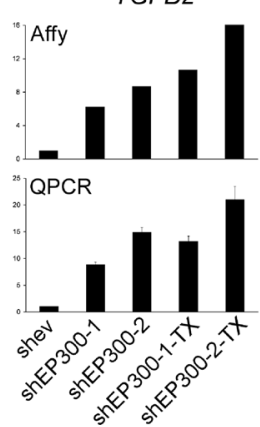

ITGA2

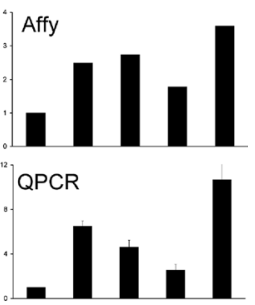

TNFRSF11B

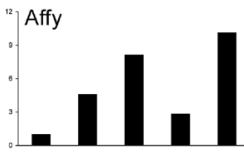

QPCR

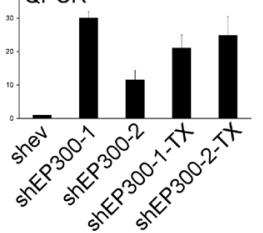

Fig. 5 Genome-wide expression profile of EP300-downregulated MCF-7 cells, and their paclitaxel-resistant derivatives. a Hierarchical clustering of differentially expressed genes. Differentially upregulated expression values are shown in red, downregulated in green. Scale represents colour values corresponding to $\lg _{2}$ expression. b, Venn diagram indicating the number of differentially expressed genes in each of the pair-wise comparisons to MCF7-shev control cells.

would be downregulated in metaplastic breast cancer. In order to detect EP300 by immunohistochemistry, we first validated a commercial antibody used for the Human Protein Atlas [31] by peptide competition (Fig. 7a). EP300 expression in normal/benign breast tissue was high in both the epithelial and stroma compartments. However, epithelial cells showed both nuclear and cytoplasmic staining, whereas cells from the stroma showed exclusively nuclear staining. As expected, E-cadherin expression was strong in the epithelial component and absent in the stroma

There were 4044 common differentially expressed genes present in all cells after downregulation of EP300. c Eleven genes were selected for validation by quantitative PCR. The top panel for each gene shows the normalized fluorescence from Affymetrix array expression data. The lower panel for each gene indicates the normalized QPCR data relative to the expression data obtained in control MCF7-shev cells. QPCR data represent the mean \pm SD from three replicates

(Fig. 7b). We analysed 17 metaplastic breast cancer samples that all scored negative or low for E-cadherin expression (scores 0 or 1) and found that all of them also scored low (score 1) for EP300 expression in the mesenchymal metaplastic component (Fig. 7b). Importantly, most of the EP300 nuclear staining was lost in metaplastic samples, their low positivity being the result of cytoplasmic expression (Fig. 7c). Eight (47\%) metaplastic breast cancers were histologically heterogeneous, mainly with the nests of squamous differentiation showing positivity for 
A
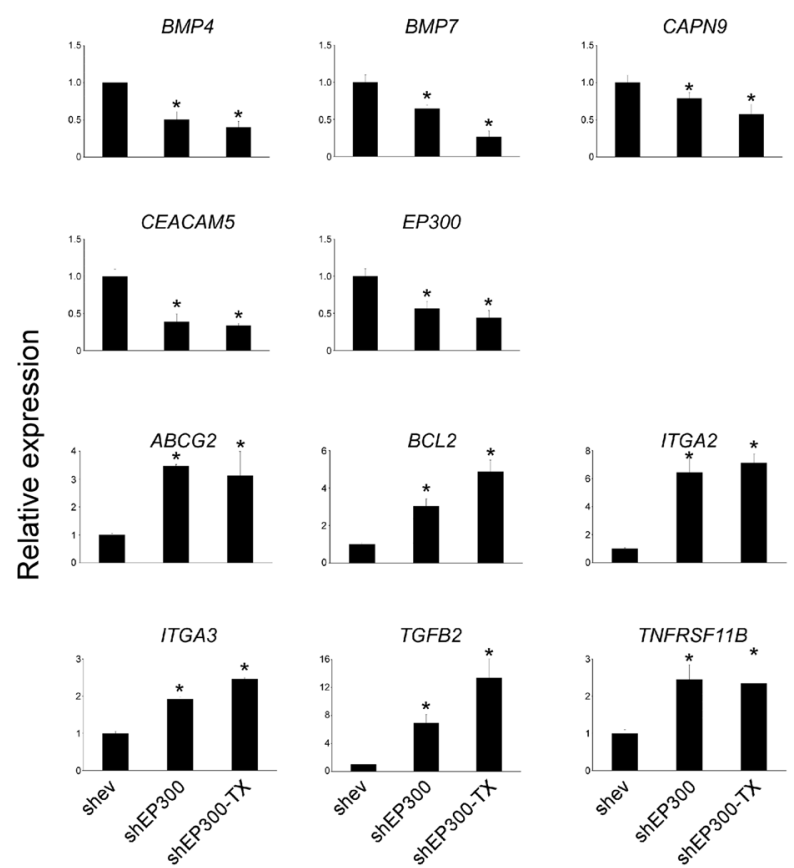

Fig. 6 Validation of the EP300 signature in other cell models. a QPCR data from EP-downregulated minimally transformed mammary epithelial cells, and their paclitaxel-resistant derivatives. The gene set is the same that is used in Fig. $5 \mathrm{c}$ to validate the MCF-7 signature. b QPCR data of anti-apoptotic $B C L 2$ and stem cell marker $A B C G 2$ from the MCF-7 signature in HCT116 cells. c and d, Bcl-2

both E-cadherin and EP300 (Fig. 7d). Due to the rarity of this type of breast cancer and the small sample size, no associations with other clinical parameters were sought. Thus, EP300 is downregulated in metaplastic breast cancer.

\section{Discussion}

We have recently described a novel pathway controlling drug resistance in breast cancer cells. Upstream of the pathway, three miRs (miR-106b, miR-93 and miR-25) transcribed from the same cluster, target EP300, a transcriptional activator of E-cadherin. Upregulation of these miRs, found in aggressive basal-like, oestrogen receptornegative, grade 3 breast cancers [13] and drug-resistant cell models, leads to a downregulation of EP300 and E-cadherin with initiation of an EMT [12]. However, miRs regulate the expression of many genes, and the contribution to EMT by miR targets other than EP300 cannot be ruled out. Here we describe that experimental modulation of EP300 in breast and colon cancer cell models alters paclitaxel sensitivity and the generation of resistant cells. Importantly, EP300 is also associated with stemness. Its downregulation is associated with increased in vitro tumorigenicity and cancer stem cell-like markers, whilst its

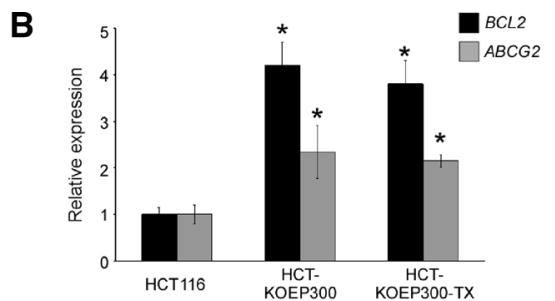

C

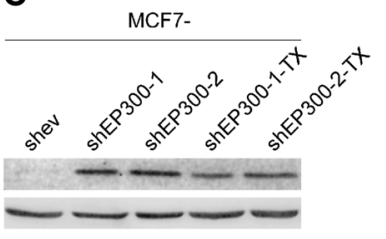

D
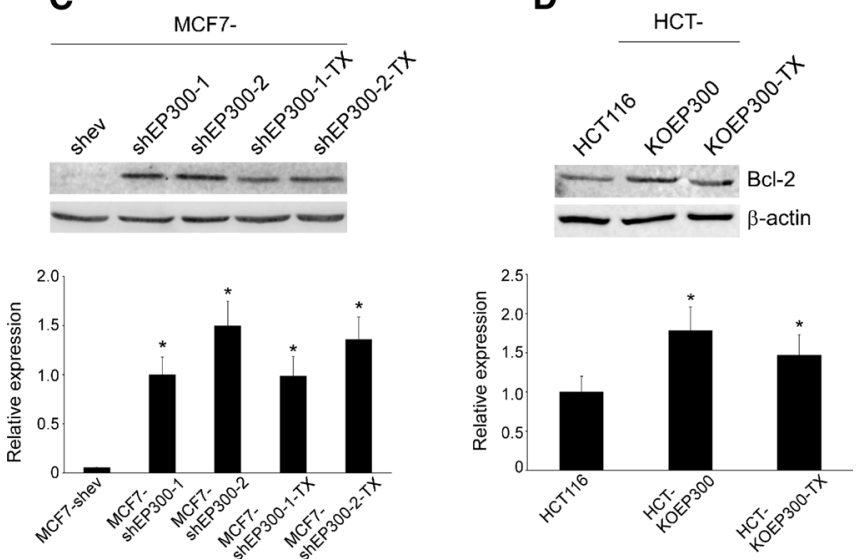

immunoblot (top panels) and blot quantification (lower panels) in both MCF-7 (c) and HCT116 (d) cell derivatives. $\beta$-actin is used as a loading control. Numerical data represent the average \pm SD of three independent experiments. All statistical comparisons $(* P<0.05)$ versus control cells. Immunoblot shows a representative of three independent experiments

ectopic expression in basal breast cancer cells partly rescues the epithelial, differentiated, paclitaxel-sensitive phenotype. Transcriptome analysis identifies key molecules associated with these phenotypes such as CEACAM5 (adhesion), CAPN9 (cytoskeletal remodelling), ABCG2 (stemness), BCL2 (apoptosis), ITAG2 and ITAG3 (migration) and TGFB2 (metastasis). Lastly, we have unveiled that EP300 is downregulated in metaplastic breast cancer, a rare aggressive form of the disease with histological evidence of EMT and poor clinical outcome.

During the initiation of the metastatic cascade, cells undergo reprogramming to a less differentiated, therapyresistant and morphologically changed phenotype [32]. As EP300 functions as a histone acetyltransferase [7], with the potential to modulate the expression of a plethora of genes, it is not surprising that its experimental downregulation in MCF-7 cells alters the expression of more than 4000 genes. Although the main function of EP300 as a transcriptional activator is well-established, such as in the case of $\mathrm{CDHI}$ (E-cadherin) transactivation [5], it may also lead to gene repression [33, 34]. Early work on MCF-7 cells expressing ribozymes specific for EP300 indicates that DNA damageinduced apoptosis is impaired in EP300-deficient cells [35]. In bladder cancer cells, experimental downregulation of EP300 leads to doxorubicin and cisplatin resistance 

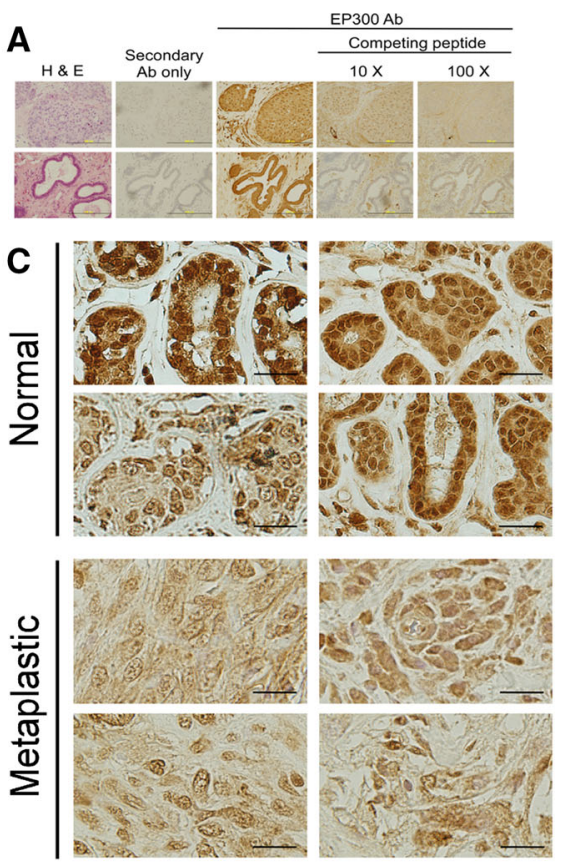

D

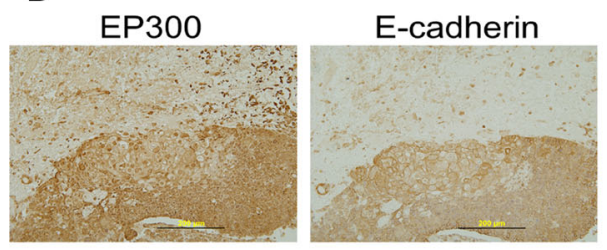

B
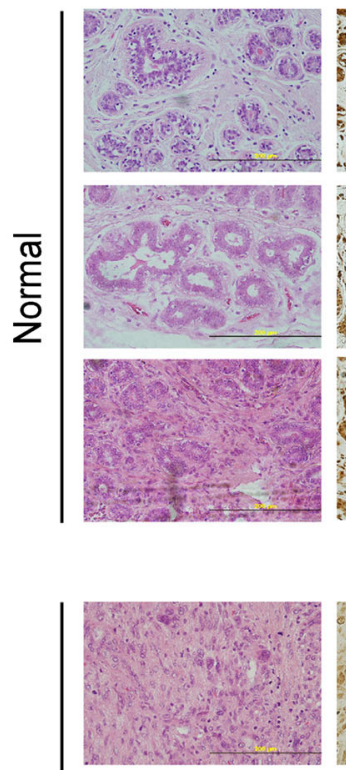

$\frac{0}{0}$
$\frac{0}{0}$
$\frac{0}{0}$
$\frac{0}{0}$
$\frac{0}{2}$

Fig. 7 EP300 is downregulated in metaplastic breast cancer. a Validation of EP300 antibody using 10- and 100-fold molar excess competing peptide in two independent breast cancer samples. $H \& E$, haematoxylin and eosin staining. Scale bar, $200 \mu \mathrm{m}$. b EP300 and E-cadherin staining in three representative samples of normal breast and metaplastic breast cancer. $H \& E$, haematoxylin and eosin staining. Scale bar, $200 \mu \mathrm{m}$. c Loss of EP300 nuclear staining in metaplastic breast cancer. Pictures show representative zoomed-in shots

$[14,15]$ and, using a minimally transformed model of mammary epithelial cells in which EP300 has been downregulated, we have recently found an impaired caspase- 9 and caspase 3/7 activation following paclitaxel treatment [17]. EP300-deficient cells show multidrug resistance to a variety of structurally and functionally different drugs and $\gamma$-radiation, a phenotype that is $\mathrm{ABC}$ transporter independent $[12,17]$. The EP300 signature presented here highlights the importance of $B C L-2$ in the apoptotic evasion reported in EP300-deficient cells. Although a definitive mechanistic insight in the regulation of apoptosis by EP300 has not yet been established, EP300 has been described to be associated with SATB1, leading to the repression of $C Y B B$, the key component of the phagocyte NADPH oxidase [36]. SATB1 has also been described to bind the $B C L-2$ promoter where it has a negative transcriptional regulatory function [37]. Other EP300-

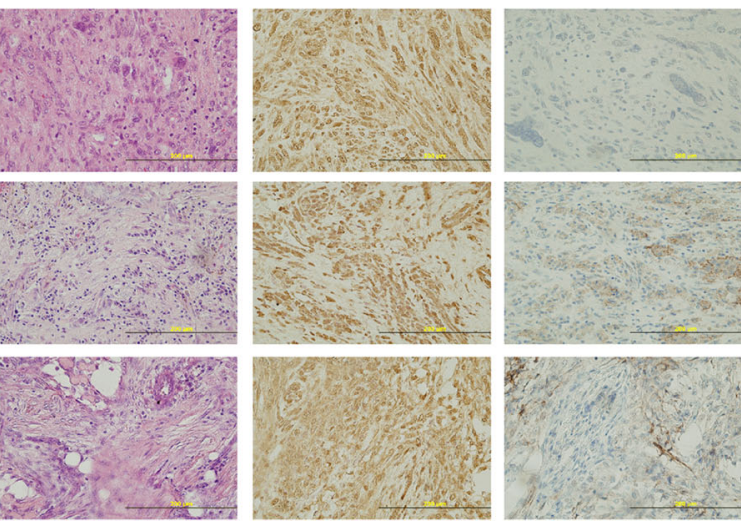

illustrating nuclear EP300 localization in normal breast and its loss in metaplastic breast cancer. Scale bar, $20 \mu \mathrm{m}$. d Representative EP300 and E-cadherin staining in a metaplastic breast cancer sample with a squamous epithelium nest (bottom half). The top half is composed of spindle-like cells. Note the absence of E-cadherin and EP300 expression in the mesenchymal component but positive staining in the squamous nest. Scale bar, $200 \mu \mathrm{m}$

associated factor, PCAF, accelerates apoptosis by repressing a GLI/BCL2/BAX axis in hepatocellular carcinoma [38]. It is thus tempting to speculate that these mechanisms may also play a role in breast cancer cells.

EP300-deficient cells increase their motility and invasive properties, both in colon and breast cancer cells [11], [12]. This phenotype involves major cellular reprogramming highlighted in the EP300 signature described here with downregulation of cell adhesion molecules, such as EPCAM5 and EPCAM6, and upregulation of collagens (COL12A1 and COL4A5) and mesenchymal OB-cadherin (CDH11), a characteristic EMT marker [39]. Upregulation of fibulins (EFEMP1 and HMCN1), which bind EGFR and regulate cell adhesion and migration, correlates with tumour progression and poor prognosis in ovarian cancer [40]. Upregulation of EPHA4, a receptor tyrosine kinase which binds ephrin family ligands, modulates cell 
morphology and promotes migration in glioma cells [41]. Consistently, high levels of EPHA4 correlate with a reduced overall survival in breast cancer patients [42]. Downregulation of ARHGAP20, a GTPase activator of Rho-type GTPases, favours Rho to be in the active GTPbound state and promotes motility [43]. Reorganization of the actin cytoskeleton is also important for cellular remodelling, with the downregulation of plastin (PLS3) and other actin-binding proteins (CNN2), as well as upregulation of WIPF1, which intervenes in the disassembly of stress fibres in favour of filopodia formation. Importantly, high expression of WIPF1 is associated with poor prognosis in breast cancer [44]. Cytoskeletal remodelling is also regulated by CAPN9, a member of the calpain family. Low CAPN9 expression has been associated with poorer clinical outcome in breast cancer patients following endocrine therapy [45].

$T G F B 2$ is one of the three highly homologous isoforms of TGF- $\beta$ found in humans. TGF- $\beta$ is a potent inducer of EMT in mammary cells, the acquisition of CSC properties and chemotherapy resistance [46, 47]. TGF- $\beta$ also induces FGFR switching, causing murine mammary epithelial cells to become sensitive to FGF2 [48]. A similar effect is observed in the EP300 signature, with upregulation of $T G F B 2$ and FGFR2. Importantly, FGF2 induces mesenchymal OB-cadherin $(\mathrm{CDH} 1 \mathrm{l})$ expression [49], also observed in EP300-deficient MCF-7 cells. Importantly, metaplastic breast cancer is enriched in the markers of CSCs and EMT [50] and we show here low EP300 expression when compared to non-cancerous breast epithelium. Transcriptome profiling of metaplastic breast cancer indicates downregulation of epithelial phenotypes, remodelling of the extracellular matrix and EMT [51, 52]. Of note that the small sample analysed by Lien et al. indicates a concordance with differentially regulated genes in the MCF-7 EP300 signature, downregulation of $\mathrm{CDH1}$, CEACAM6 and ARHGAP8, another Rho GTPase-activating protein, as well as upregulation of $B C L 2 A 1, E F N B 1$ (ephrin B1) and osteoprotegerin (TNFRSF11B), a soluble TRAIL decoy receptor secreted by inflammatory and invasive breast cancer cells that induces aneuploidy, cell proliferation and angiogenesis [53].

In conclusion, we demonstrate that tumour suppressor EP300 is poorly expressed in metaplastic breast cancer and is a master regulator of EMT, CSCs and drug resistance.

\footnotetext{
Acknowledgements We thank William Hahn (Dana Farber, Boston) for a generous gift of human minimally transformed mammary epithelial cells (MTMEC), Parmjit Jat (Medical Research Council, UK) for EP300 hairpin clones and Warner Green (University of California at San Francisco) for pcDNA3.1-p300. We thank Laurence Game and MRC CSC Genomics Facility members for advice on transcriptome analysis and members of the Centre for Pathology, Charing Cross Hospital, for advice on immunohistochemistry.
}

Funding This study was funded by Breast Cancer Now (to EY, EWL and SS), Cancer Research UK (to RCC, SA, EWL and EY), the Chinese National Natural Sciences Foundation (to YH) and the Science and Technology Foundation of Tianjin Municipal Health Bureau (to $\mathrm{YH}$ ). We thank the Imperial BRC and ECMC for support. MA was supported by a fellowship from the Commonwealth Scholarship Council.

\section{Compliance with ethical standards}

Conflict of interest The authors declare that they have no competing interests.

Ethical approval All procedures performed in studies involving human participants were in accordance with the ethical standards of the Imperial College Healthcare Tissue Bank (R14086) and Breast Cancer Now Tissue Bank (BCNTB-TR000054) and with the 1964 Helsinki declaration and its later amendments or comparable ethical standards.

Open Access This article is distributed under the terms of the Creative Commons Attribution 4.0 International License (http://crea tivecommons.org/licenses/by/4.0/), which permits unrestricted use, distribution, and reproduction in any medium, provided you give appropriate credit to the original author(s) and the source, provide a link to the Creative Commons license, and indicate if changes were made.

\section{References}

1. Sledge GW, Mamounas EP, Hortobagyi GN, Burstein HJ, Goodwin PJ, Wolff AC (2014) Past, present, and future challenges in breast cancer treatment. $J$ Clin Oncol 32(19):1979-1986. doi:10.1200/JCO.2014.55.4139

2. Mani SA, Guo W, Liao MJ, Eaton EN, Ayyanan A, Zhou AY, Brooks M, Reinhard F, Zhang CC, Shipitsin M, Campbell LL, Polyak K, Brisken C, Yang J, Weinberg RA (2008) The epithelial-mesenchymal transition generates cells with properties of stem cells. Cell 133(4):704-715. doi:10.1016/j.cell.2008.03.027

3. Singh A, Settleman J (2010) EMT, cancer stem cells and drug resistance: an emerging axis of evil in the war on cancer. Oncogene 29(34):4741-4751. doi:10.1038/onc.2010.215

4. Dave B, Mittal V, Tan NM, Chang JC (2012) Epithelial-mesenchymal transition, cancer stem cells and treatment resistance. Breast Cancer Res 14(1):202. doi:10.1186/bcr2938

5. Liu YN, Lee WW, Wang CY, Chao TH, Chen Y, Chen JH (2005) Regulatory mechanisms controlling human E-cadherin gene expression. Oncogene 24(56):8277-8290

6. Kalkhoven E (2004) CBP and p300: HATs for different occasions. Biochem Pharmacol 68(6):1145-1155. doi:10.1016/j.bcp. 2004.03.045

7. Ogryzko VV, Schiltz RL, Russanova V, Howard BH, Nakatani Y (1996) The transcriptional coactivators $\mathrm{p} 300$ and CBP are histone acetyltransferases. Cell 87(5):953-959

8. Goodman RH, Smolik S (2000) CBP/p300 in cell growth, transformation, and development. Genes Dev 14(13):1553-1577

9. Bryan EJ, Jokubaitis VJ, Chamberlain NL, Baxter SW, Dawson E, Choong DY, Campbell IG (2002) Mutation analysis of EP300 in colon, breast and ovarian carcinomas. Int $\mathrm{J}$ Cancer 102(2):137-141. doi:10.1002/ijc.10682

10. Gayther SA, Batley SJ, Linger L, Bannister A, Thorpe K, Chin SF, Daigo Y, Russell P, Wilson A, Sowter HM, Delhanty JD, Ponder BA, Kouzarides T, Caldas C (2000) Mutations truncating 
the EP300 acetylase in human cancers. Nat Genet 24(3):300-303. doi:10.1038/73536

11. Krubasik D, Iyer NG, English WR, Ahmed AA, Vias M, Roskelley C, Brenton JD, Caldas C, Murphy G (2006) Absence of p300 induces cellular phenotypic changes characteristic of epithelial to mesenchyme transition. $\mathrm{Br} \mathrm{J}$ Cancer 94(9):1326-1332. doi:10.1038/sj.bjc.6603101

12. Zhou Y, Hu Y, Yang M, Jat P, Li K, Lombardo Y, Xiong D, Coombes RC, Raguz S, Yague E (2014) The miR-106b $\sim 25$ cluster promotes bypass of doxorubicin-induced senescence and increase in motility and invasion by targeting the E-cadherin transcriptional activator EP300. Cell Death Differ 21(3):462-474. doi:10.1038/cdd.2013.167

13. Blenkiron C, Goldstein LD, Thorne NP, Spiteri I, Chin SF, Dunning MJ, Barbosa-Morais NL, Teschendorff AE, Green AR, Ellis IO, Tavare S, Caldas C, Miska EA (2007) MicroRNA expression profiling of human breast cancer identifies new markers of tumor subtype. Genome Biol 8(10):R214

14. Shiota M, Yokomizo A, Kashiwagi E, Tada Y, Inokuchi J, Tatsugami K, Kuroiwa K, Uchiumi T, Seki N, Naito S (2010) Foxo3a expression and acetylation regulate cancer cell growth and sensitivity to cisplatin. Cancer Sci 101(5):1177-1185. doi:10. 1111/j.1349-7006.2010.01503.x

15. Takeuchi A, Shiota M, Tatsugami K, Yokomizo A, Tanaka S, Kuroiwa K, Eto M, Naito S (2012) p300 mediates cellular resistance to doxorubicin in bladder cancer. Mol Med Rep 5(1):173-176. doi:10.3892/mmr.2011.593

16. Zhao JJ, Gjoerup OV, Subramanian RR, Cheng Y, Chen W, Roberts TM, Hahn WC (2003) Human mammary epithelial cell transformation through the activation of phosphatidylinositol 3-kinase. Cancer Cell 3(5):483-495

17. Hu Y, Li K, Asaduzzaman M, Cuella R, Shi H, Raguz S, Coombes RC, Zhou Y, Yague E (2016) miR-106b 25 cluster regulates multidrug resistance in an $\mathrm{ABC}$ transporter-independent manner via downregulation of EP300. Oncol Rep 35:1170-1178. doi:10.3892/or.2015.4412

18. Raguz S, Adams C, Masrour N, Rasul S, Papoutsoglou P, Hu Y, Cazzanelli G, Zhou Y, Patel N, Coombes C, Yague E (2013) Loss of $\mathrm{O}(6)$-methylguanine-DNA methyltransferase confers collateral sensitivity to carmustine in topoisomerase II-mediated doxorubicin resistant triple negative breast cancer cells. Biochem Pharmacol 85(2):186-196. doi:10.1016/j.bcp.2012.10.020

19. Chen LF, Mu Y, Greene WC (2002) Acetylation of RelA at discrete sites regulates distinct nuclear functions of NF-kappaB. EMBO J 21(23):6539-6548

20. Yague E, Armesilla AL, Harrison G, Elliott J, Sardini A, Higgins CF, Raguz S (2003) P-glycoprotein (MDR1) expression in leukemic cells is regulated at two distinct steps, mRNA stabilization and translational initiation. J Biol Chem 278(12):10344-10352

21. Vichai V, Kirtikara K (2006) Sulforhodamine B colorimetric assay for cytotoxicity screening. Nat Protoc 1(3):1112-1116

22. Rasul S, Balasubramanian R, Filipovic A, Slade MJ, Yague E, Coombes RC (2009) Inhibition of gamma-secretase induces G2/ $\mathrm{M}$ arrest and triggers apoptosis in breast cancer cells. Br J Cancer 100(12):1879-1888. doi:10.1038/sj.bjc.6605034

23. Lombardo Y, Filipovic A, Molyneux G, Periyasamy M, Giamas G, Hu Y, Trivedi PS, Wang J, Yague E, Michel L, Coombes RC (2012) Nicastrin regulates breast cancer stem cell properties and tumor growth in vitro and in vivo. Proc Natl Acad Sci USA 109(41):16558-16563. doi:10.1073/pnas.1206268109

24. Liu LK, Jiang XY, Zhou XX, Wang DM, Song XL, Jiang HB (2010) Upregulation of vimentin and aberrant expression of E-cadherin/beta-catenin complex in oral squamous cell carcinomas: correlation with the clinicopathological features and patient outcome. Mod Pathol 23(2):213-224. doi:10.1038/modpathol. 2009.160
25. Ginestier C, Hur MH, Charafe-Jauffret E, Monville F, Dutcher J, Brown M, Jacquemier J, Viens P, Kleer CG, Liu S, Schott A, Hayes D, Birnbaum D, Wicha MS, Dontu G (2007) ALDH1 is a marker of normal and malignant human mammary stem cells and a predictor of poor clinical outcome. Cell Stem Cell 1(5):555-567. doi:10.1016/j.stem.2007.08.014

26. Calcagno AM, Salcido CD, Gillet JP, Wu CP, Fostel JM, Mumau MD, Gottesman MM, Varticovski L, Ambudkar SV (2010) Prolonged drug selection of breast cancer cells and enrichment of cancer stem cell characteristics. J Natl Cancer Inst 102(21):1637-1652

27. Kao J, Salari K, Bocanegra M, Choi YL, Girard L, Gandhi J, Kwei KA, Hernandez-Boussard T, Wang P, Gazdar AF, Minna JD, Pollack JR (2009) Molecular profiling of breast cancer cell lines defines relevant tumor models and provides a resource for cancer gene discovery. PLoS One 4(7):e6146. doi:10.1371/jour nal.pone. 0006146

28. Calvet CY, Andre FM, Mir LM (2014) The culture of cancer cell lines as tumorspheres does not systematically result in cancer stem cell enrichment. PLoS One 9(2):e89644. doi:10.1371/jour nal.pone. 0089644

29. Schwartz TL, Mogal H, Papageorgiou C, Veerapong J, Hsueh EC (2013) Metaplastic breast cancer: histologic characteristics, prognostic factors and systemic treatment strategies. Exp Hematol Oncol 2(1):31. doi:10.1186/2162-3619-2-31

30. Weigelt B, Eberle C, Cowell CF, Ng CK, Reis-Filho JS (2014) Metaplastic breast carcinoma: more than a special type. Nat Rev Cancer 14(3): 147-148

31. Ponten F, Jirstrom K, Uhlen M (2008) The human protein atlas-a tool for pathology. J Pathol 216(4):387-393. doi:10.1002/path. 2440

32. Chaffer CL, Weinberg RA (2011) A perspective on cancer cell metastasis. Science 331(6024):1559-1564. doi:10.1126/science. 1203543

33. Snowden AW, Anderson LA, Webster GA, Perkins ND (2000) A novel transcriptional repression domain mediates p21(WAF1/ CIP1) induction of p300 transactivation. Mol Cell Biol 20(8):2676-2686

34. Girdwood D, Bumpass D, Vaughan OA, Thain A, Anderson LA, Snowden AW, Garcia-Wilson E, Perkins ND, Hay RT (2003) P300 transcriptional repression is mediated by SUMO modification. Mol Cell 11(4):1043-1054

35. Yuan ZM, Huang Y, Ishiko T, Nakada S, Utsugisawa T, Shioya H, Utsugisawa Y, Shi Y, Weichselbaum R, Kufe D (1999) Function for $\mathrm{p} 300$ and not CBP in the apoptotic response to DNA damage. Oncogene 18(41):5714-5717. doi:10.1038/sj.onc. 1202930

36. Fujii Y, Kumatori A, Nakamura M (2003) SATB1 makes a complex with p300 and represses gp91(phox) promoter activity. Microbiol Immunol 47(10):803-811

37. Gong F, Sun L, Sun Y (2010) A novel SATB1 binding site in the BCL2 promoter region possesses transcriptional regulatory function. J Biomed Res 24(6):452-459. doi:10.1016/S16748301(10)60060-7

38. Gai X, Tu K, Li C, Lu Z, Roberts LR, Zheng X (2015) Histone acetyltransferase PCAF accelerates apoptosis by repressing a GLI1/BCL2/BAX axis in hepatocellular carcinoma. Cell Death Dis 6:e1712. doi:10.1038/cddis.2015.76

39. Zeisberg M, Neilson EG (2009) Biomarkers for epithelial-mesenchymal transitions. J Clin Investig 119(6):1429-1437. doi:10. 1172/JCI36183

40. Chen J, Wei D, Zhao Y, Liu X, Zhang J (2013) Overexpression of EFEMP1 correlates with tumor progression and poor prognosis in human ovarian carcinoma. PLoS One 8(11):e78783. doi:10.1371/ journal.pone.0078783

41. Fukai J, Yokote $\mathrm{H}$, Yamanaka R, Arao T, Nishio K, Itakura $\mathrm{T}$ (2008) EphA4 promotes cell proliferation and migration through 
a novel EphA4-FGFR1 signaling pathway in the human glioma U251 cell line. Mol Cancer Ther 7(9):2768-2778. doi:10.1158/ 1535-7163.MCT-07-2263

42. Brantley-Sieders DM, Jiang A, Sarma K, Badu-Nkansah A, Walter DL, Shyr Y, Chen J (2011) Eph/ephrin profiling in human breast cancer reveals significant associations between expression level and clinical outcome. PLoS One 6(9):e24426. doi:10.1371/ journal.pone. 0024426

43. Katoh M, Katoh M (2003) Identification and characterization of human KIAA1391 and mouse Kiaa1391 genes encoding novel RhoGAP family proteins with RA domain and ANXL repeats. Int J Oncol 23(5):1471-1476

44. Staub E, Groene J, Heinze M, Mennerich D, Roepcke S, Klaman I, Hinzmann B, Castanos-Velez E, Pilarsky C, Mann B, Brummendorf T, Weber B, Buhr HJ, Rosenthal A (2009) An expression module of WIPF1-coexpressed genes identifies patients with favorable prognosis in three tumor types. $\mathrm{J}$ Mol Med 87(6):633-644. doi:10.1007/s00109-009-0467-y

45. Davis J, Martin SG, Patel PM, Green AR, Rakha EA, Ellis IO, Storr SJ (2014) Low calpain-9 is associated with adverse diseasespecific survival following endocrine therapy in breast cancer. BMC Cancer 14:995. doi:10.1186/1471-2407-14-995

46. Akhurst RJ, Hata A (2012) Targeting the TGFbeta signalling pathway in disease. Nat Rev Drug Discov 11(10):790-811. doi: $10.1038 / \operatorname{nrd} 3810$

47. Bhola NE, Balko JM, Dugger TC, Kuba MG, Sanchez V, Sanders M, Stanford J, Cook RS, Arteaga CL (2013) TGF-beta inhibition enhances chemotherapy action against triple-negative breast cancer. J Clin Investig 123(3):1348-1358. doi:10.1172/JCI65416
48. Shirakihara T, Horiguchi K, Miyazawa K, Ehata S, Shibata T, Morita I, Miyazono K, Saitoh M (2011) TGF-beta regulates isoform switching of FGF receptors and epithelial-mesenchymal transition. EMBO J 30(4):783-795. doi:10.1038/emboj.2010.351

49. Strutz F, Zeisberg M, Ziyadeh FN, Yang CQ, Kalluri R, Muller GA, Neilson EG (2002) Role of basic fibroblast growth factor-2 in epithelial-mesenchymal transformation. Kidney Int 61(5):1714-1728. doi:10.1046/j.1523-1755.2002.00333.x

50. Zhang Y, Toy KA, Kleer CG (2012) Metaplastic breast carcinomas are enriched in markers of tumor-initiating cells and epithelial to mesenchymal transition. Mod Pathol 25(2):178-184. doi:10.1038/modpathol.2011.167

51. Lien HC, Hsiao YH, Lin YS, Yao YT, Juan HF, Kuo WH, Hung MC, Chang KJ, Hsieh FJ (2007) Molecular signatures of metaplastic carcinoma of the breast by large-scale transcriptional profiling: identification of genes potentially related to epithelialmesenchymal transition. Oncogene 26(57):7859-7871. doi:10. 1038/sj.onc. 1210593

52. Weigelt B, Kreike B, Reis-Filho JS (2009) Metaplastic breast carcinomas are basal-like breast cancers: a genomic profiling analysis. Breast Cancer Res Treat 117(2):273-280. doi:10.1007/ s10549-008-0197-9

53. Goswami S, Sharma-Walia N (2015) Osteoprotegerin secreted by inflammatory and invasive breast cancer cells induces aneuploidy, cell proliferation and angiogenesis. BMC Cancer 15:935. doi:10.1186/s12885-015-1837-1 